\title{
Does Harboring Hostility Hurt? Associations Between Hostility and Pulmonary Function in the Coronary Artery Risk Development in (Young) Adults (CARDIA) Study
}

\author{
Benita Jackson \\ Smith College \\ Sheldon Cohen \\ Carnegie Mellon University
}

\author{
Laura D. Kubzansky \\ Harvard University \\ David R. Jacobs, Jr. \\ University of Minnesota and University of Oslo
}

\author{
Rosalind J. Wright \\ Harvard Medical School/Brigham and Women's Hospital and Harvard University
}

\begin{abstract}
Objective: To examine the cross-sectional association between hostility and pulmonary function (PF) and its consistency across race/ethnicity-gender groups. Design: Data were from the Coronary Artery Risk Development in (Young) Adults (CARDIA) cohort study $(N=4,629)$. Participants were recruited from 4 metropolitan areas in the United States, ages 18-30 years at baseline in 1985-1986, approximately balanced across race/ethnicity (Black, White) and gender. Main Outcome Measures: Main outcome measures were percent predicted values for forced expiratory volume in 1 second $\left(\mathrm{FEV}_{1}\right)$ and forced vital capacity (FVC). Results: In full-sample multiple linear regression analyses, each 1 standard deviation $(S D)$ increase in hostility was associated with a $0.66 \%$ decrease in $\operatorname{FEV}_{1}(p=.0002)$ and a $0.60 \%$ decrease in $\operatorname{FVC}(p=.0006)$. This inverse association of hostility with $\mathrm{PF}$ remained after controlling for age, height, current socioeconomic status (SES), participant smoking status, and asthma and is more consistent than that of smoking and PF. In stratified analyses, each $1 S D$ increase in hostility predicted statistically significant reductions in PF for Black women, White women, and Black men. For White men, hostility showed no statistically significant relation with PF, although the pattern relating hostility to PF was similar to the pattern in the other three groups. Further, both of the post hoc three-way interaction terms for hostility, race/ethnicity, and gender predicting $\mathrm{FEV}_{1}$ and FVC were nonsignificant. Conclusion: PF was inversely associated with hostility across race/ethnicity and gender, independent of age, height, current SES, smoking, and asthma. On the basis of these cross-sectional findings, the authors hypothesize that higher hostility will predict a more rapid decline in PF.
\end{abstract}

Keywords: hostility, pulmonary function, CARDIA study, race/ethnicity, gender

Chronic obstructive pulmonary disease (COPD) is a progressive, only partially reversible condition characterized by reduced airflow to the lungs, resulting in significant associated morbidity and mortality (Calverley \& Walker, 2003; Senior \& Anthonisen,
Benita Jackson, Department of Psychology, Clark Science Center, Smith College; Laura D. Kubzansky, Department of Society, Human Development, and Health, Harvard School of Public Health, Harvard University; Sheldon Cohen, Department of Psychology, Carnegie Mellon University; David R. Jacobs, Jr., Division of Epidemiology, University of Minnesota School of Public Health, and Department of Nutrition, University of Oslo, Oslo, Norway; Rosalind J. Wright, Harvard Medical School, Harvard University/Channing Laboratory, Department of Medicine, Brigham and Women's Hospital, Boston, Massachusetts, and Department of Society, Human Development, and Health, Harvard School of Public Health, Harvard University.

The Coronary Artery Risk Development in (Young) Adults (CARDIA) study is conducted and supported by the National Heart, Lung, and Blood Institute (NHLBI) in collaboration with the CARDIA study investigators. This article has been reviewed by NHLBI and the CARDIA steering committee for scientific content and consistency of data interpretation with previous CARDIA study publications, and significant comments were incorporated prior to submission for publication.

These analyses were supported by the MacArthur Foundation Network on Socioeconomic Status and Health. During the preparation of this article, we were supported in part by grants from NHLBI; the National Institute of Environmental and Health Sciences; and the National Institute of Mental Health. Prior to her affiliation at Smith College, Benita Jackson was a postdoctoral fellow at Channing Laboratory, supported by Training Grant HL07427; Laura D. Kubzansky was supported by Grant ES10932; Sheldon Cohen was supported by the Pittsburgh National Institutes of Health Mind-Body Center (Grants HL65111 and HL65112); David R. Jacobs, Jr., was supported by Grant N01-HC-48048 (to the CARDIA field center in Minnesota); and Rosalind J. Wright was supported by Grants K08 HL04187 and ES10932. Other CARDIA data collection was supported by Grants N01-HC-48047, N01-HC-48049, N01-HC-48050, and N01-HC95095. Thanks to Marina Jacobson Canner for expert assistance with data setup and manuscript preparation.

Correspondence concerning this article should be addressed to Benita Jackson, Department of Psychology, Clark Science Center, 44 College Lane, Smith College, Northampton, MA 01063. E-mail: bjackson@email.smith.edu 
1998). As of 1990, COPD was the sixth most common cause of death worldwide; it has been projected to become the third leading cause of death by the year 2020 (Murray \& Lopez, 1997). Several risk factors have been identified, most notably smoking (Senior \& Anthonisen, 1998). Others include occupational exposures, indoor air pollution, childhood infections, prenatal exposures, airway reactivity, and genetic predisposition (Calverley \& Walker, 2003; Senior \& Anthonisen, 1998). To date, these risk factors do not adequately explain individual differences in who develops COPD.

Level of pulmonary function is used as a reliable risk marker of COPD (Senior \& Anthonisen, 1998). Pulmonary function reaches a peak and then plateaus during young adulthood (Apostol et al., 2002). The highest level of pulmonary function attained sets the stage for health in later life (Wang, Mensinga, Schouten, Rijcken, $\&$ Weiss, 2004). Research indicates that those who rapidly decline in pulmonary function during older adult years are at increased risk for morbidity and mortality (Pelkonen et al., 2001). Higher maximally attained pulmonary function in young adulthood affords a greater buffer from later rapid decline (Wang et al., 2004). Therefore, even seemingly small disparities in pulmonary function that appear during young adulthood may be amplified over time and exert substantial influence on later life health.

Numerous studies have suggested that psychological factors like hostility adversely affect physical health. In particular, a considerable body of evidence suggests an important role for hostility in the development of coronary heart disease (for a review, see Miller, Smith, Turner, Guijarro, \& Hallet, 1996). For example, in a 9-year follow-up study of 1,599 men ages 42-60 years who were initially disease free, men with the highest levels of hostility were at two times the risk of myocardial infarction relative to men with the lowest levels of hostility (relative hazard ratio $=2.18,95 \%$ confidence interval $=1.01$, 4.70; Everson et al., 1997). There is also evidence for an association between hostility and hypertension (Yan et al., 2003), the metabolic syndrome (Niaura et al., 2000), and all-cause mortality (Miller et al., 1996).

Taken together, studies to date strongly suggest a role for hostility in cardiovascular-related outcomes. Notably, pulmonary function is inversely related to cardiovascular disease and premature mortality (Weiss, 1991), which suggests hostility could play a role in pulmonary health as well. In fact, proposed mechanisms by which hostility influences health are not necessarily specific to cardiovascular health. Hostility has been associated with a wide array of health risk factors, ranging from dysregulated neuroendocrine function to smoking behavior to alcohol consumption to social isolation (Siegler et al., 2003).

Following the theoretical model linking affective disturbances to physical disorders set forth by Cohen and Rodriguez (1995), we identify several biological pathways by which hostility may be associated with pulmonary function. Researchers have found associations of hostility with immune system (fibrinogen; Pollitt et al., 2005), sympathetic nervous system (Hughes, Sherwood, Blumenthal, Suarez, \& Hinderliter, 2003), hypothalamic-pituitaryadrenal axis (Butovskaya, Boyko, Selverova, \& Ermakova, 2005); and endocrine (leptin; Atmaca, Kuloglu, Tezcan, Gecici, \& Ustundag, 2002) activity. In turn, links have been identified between each of these biological pathways and pulmonary function: fibrinogen levels (Donaldson et al., 2005), $\beta$-adrenergic responsiveness (van der Velden \& Hulsmann, 1999), cortisol dysregulation (Sparrow, O'Connor, Rosner, Demolles, \& Weiss, 1993), and leptin secretion (Sin \& Man, 2003). Thus, we believe it is reasonable to speculate an association between hostility and pulmonary function, given these few examples of a likely much wider array of plausible mechanisms.

Although there is an emerging literature on the inverse associations of anxiety and depression with pulmonary function among people with preexisting respiratory diseases, like asthma (Katon, Richardson, Lozano, \& McCauley, 2004; Ritz \& Steptoe, 2000) or COPD (Crockett, Cranston, Moss, \& Alpers, 2002), scant research has examined the association of any psychosocial factors with pulmonary function in more representative disease-free populations. One recent study found a protective effect of optimism on pulmonary function among older men (Kubzansky et al., 2002). However, we know of no research to date that has focused directly on the association between hostility and pulmonary function.

Notably, rates of COPD are increasing disproportionately for women and people of color (Hurd, 2000), which suggests that explanations for the recent increases in this disease must consider these groups carefully. Women and people of color are often in positions of low social status. As a result, they are not only more likely to be exposed disproportionately to physical hazards because of workplace or home exposure but also likely to confront more adversity and have fewer opportunities for positive experiences than those in higher status positions (Sidanius \& Pratto, 1999). Further, those who live lower in the social hierarchy may repeatedly find themselves in situations that elicit others', as well as their own, hostile behaviors and feelings. The persistent adversity they face may call for coping in ways that are adaptive on a short-term basis and effective in circumscribed contexts but that compromise long-term health (Houston \& Vavak, 1991). One such example is using aggression to minimize further threats and maintain safety in poor urban contexts (Tolan, Gorman-Smith, Henry, Chung, \& Hunt, 2002). Although such behavior may be adaptive in the short term, it also creates more opportunities for injury as well as further hostile interactions. Another example is that higher hostility has been associated with smoking cigarettes, drinking alcohol, and consuming high-fat foods (Siegler et al., 2003), which may reflect efforts to decrease negative affect (Cooper, Frone, Russell, \& Mudar, 1995; Jackson, Cooper, Mintz, \& Albino, 2003).

One study of young adults examined a host of risk factors for cardiovascular disease, including lowered pulmonary function; a secondary finding of a simple correlation between hostility and lowered forced expiratory volume in 1 second $\left(\mathrm{FEV}_{1}\right)$ was briefly reported for all examined race/ethnicity (Black, White) and gender (female, male) groups except White men (Higgins et al., 1991). The current investigation picks up on this provocative but littlestudied finding and explores it in depth using the same data set. The goal of our study was to examine the association between hostility and pulmonary function during young adulthood and test the consistency of effects across different racial/ethnic and gender groups while controlling for a variety of potential confounders. We asked the question, "Is hostility similarly harmful for women and for men, for Blacks and for Whites?" By using data from the Coronary Artery Risk Development in (Young) Adults (CARDIA) study, we examined the relationship between hostility and two objective, reliable, and well-regarded indices of pulmonary function: $\mathrm{FEV}_{1}$ and forced vital capacity (FVC). As well, we compared women and men, and Blacks and Whites, as relatively healthy 
young adults, taking account of a range of potential confounders. Because maximal pulmonary capacity is attained in young adulthood and implicated in the subsequent developmental course of pulmonary function, young adulthood is an important period in which to study the relationships between hostility and pulmonary function. Exposures and behaviors during this time lay the groundwork for adult hostility and later life health outcomes (Houston \& Vavak, 1991).

We hypothesized an inverse relationship between hostility and pulmonary function; that is, with higher hostility, we expected to see poorer pulmonary function. We expected this relationship to persist even when accounting for standard control variables such as age and height, as well as current socioeconomic status (SES), smoking status, and asthma. We hypothesized that the pattern of this association would be similar for all racial/ethnic and gender groups: Black women, White women, Black men, and White men. However, given previous reports that Blacks report more hostility than do Whites and that men report more hostility than do women, we expected absolute levels of hostility to vary across these groups.

\section{Method}

The CARDIA study was designed to assess evolution of cardiovascular risk factors in young adults. The human studies committees of the Brigham and Women's Hospital and each of the CARDIA sites approved the study. Details about study design and recruitment are available elsewhere (Friedman et al., 1988).

The study was conducted in four urban centers in the United States: Minneapolis, MN; Birmingham, AL; Chicago, IL; and Oakland, CA. The following participants were included: those who self-identified as Black or as White (U.S. Census Bureau category), with a permanent address in the target area, free of longterm disease or disability, and not pregnant at baseline. All data for the current analyses were from baseline (1985-1986). Fifty percent of eligible individuals, ages 18-30 years, took part in the study, resulting in a total sample of 5,115 participants $(2,787$ women and 2,328 men) approximately balanced within each center across gender, race/ethnicity, and SES. The inclusion criterion for the current analyses was having complete assessments on each measure used for this study, yielding a final sample of 4,629.

\section{Measures}

Hostility. Hostility was measured using the Cook-Medley Questionnaire, which is derived from a subset of items from the Minnesota Multiphasic Personality Inventory (Cook \& Medley, 1954) and has been used in other epidemiological studies (Miller et al., 1996). Respondents answered true or false to each of the 50 items; scale scores could range from 0 to 50 , with higher scores indicating greater hostility. We used hostility measured as a continuous variable and checked goodness-of-fit using mean pulmonary function according to quintiles of hostility. Hostility was deemed missing if one or more of the items used to compute it were missing. Hostility score was missing for 199 participants, who showed no statistically significant differences compared with the rest of the sample on any of the remaining predictor variables: age, height, current SES operationalized by current education, smoking, and asthma.
Other correlates of pulmonary function. Participant race/ ethnicity, gender, age, current SES, smoking status, and asthma were ascertained by an interviewer-administered questionnaire. Current SES was indexed by number of years of education the participant had completed at the time of the interview. Following previous research (Apostol et al., 2002), asthma was defined in two levels. The first was self-reported asthma symptoms without asthma diagnosis, namely shortness of breath "when hurrying on the level or walking up a slight hill" in conjunction with wheezing (either apart from colds or most days or nights). The second asthma level was self-reported doctor or nurse diagnosis of asthma or the participant receiving asthma medication (medicine containers checked), regardless of symptoms. Height was measured without shoes to the nearest $0.5 \mathrm{~cm}$.

Pulmonary function. Assessments of $\mathrm{FEV}_{1}$ and FVC were obtained with a Collins Survey 8-L water-sealed spirometer and the Eagle II Microprocessor (Warren E. Collins, Inc., Braintree, MA) while participants were standing and wearing nose clips. $\mathrm{FEV}_{1}$ is an indicator of upper airway pulmonary obstruction, and FVC is an indicator of total lung volume. Pulmonary function data were acceptable if at least three reproducible (within $10 \%$ of each other) tests of $\mathrm{FEV}_{1}$ and FVC were performed out of up to five attempts, in accordance with American Thoracic Society standards for pulmonary function. Of the 5,115 CARDIA participants, 4,861 (95\%) yielded acceptable data for $\mathrm{FEV}_{1}$ and FVC. Percent predicted equations - derived from large population-based samplesare used to determine how close the observed data are to values expected for a given individual. Using the equations set forth by Hankinson and colleagues (Hankinson, Odencrantz, \& Fedan, 1999), we calculated corresponding percent predicted values as the observed pulmonary function value multiplied by 100 and then divided by the individually predicted pulmonary function value. Although the percent predicted values are designed to remove associations with race/ethnicity, gender, age, and height, we found some residual confounding when we adjusted race/ethnicity- and gender-specific models for age, age squared, and height. We therefore included these variables in the reduced and full models (see below).

\section{Analyses}

The analyses are in two parts, performed using SAS Version 9. All analyses were run stratified by race/ethnicity and gender (Black women, White women, Black men, and White men). First, we computed descriptive statistics for hostility and pulmonary function, as well as other contributors to pulmonary function. Second, using multiple linear regression models, we examined the associations between hostility as a continuous variable and pulmonary function. Hostility was scaled in 1 standard deviation $(S D)$ units to enhance interpretability. We ran two versions of each model: reduced (Model 1) and fully adjusted controlling for known potential confounders (Model 2). The reduced model used hostility as the independent variable of interest and used age, age squared, and height as covariates. The fully adjusted model used the variables in the reduced model and further included current SES, smoking status, and asthma as covariates. We evaluated effects on percent predicted $\mathrm{FEV}_{1}$ and FVC in separate models. 


\section{Results}

Table 1 presents descriptive statistics on hostility, pulmonary function, and contributors to pulmonary function, stratified by race/ethnicity and gender group. Using a 2 (race/ethnicity) $\times 2$ (gender) analysis of variance model (unadjusted for covariates), we found that both race/ethnicity, $F(1,4625)=466.03, p<.0001$, and gender, $F(1,4625)=98.22, p<.0001$, were associated with hostility. The interaction of race/ethnicity and gender was marginally associated with hostility, $F(1,4625)=3.41, p=.0649$. Mean hostility was highest in Black men, followed by Black women, White men, and White women (Scherwitz, Perkins, Chesney, \& Hughes, 1991). In a corresponding model, we found that both race/ethnicity, $F(1,4625)=1,428.35, p<.0001$, and gender, $F(1$, $4625)=4,553.59, p<.0001$, were associated with $\mathrm{FEV}_{1}$. Further, the Race/Ethnicity $\times$ Gender interaction was significant, $F(1$, $4625)=34.22, p<.0001$. For FVC, we found similar results: Both race/ethnicity, $F(1,4625)=1,781.63, p<.0001$, and gender, $F(1,4625)=5,760.77, p<.0001$, were associated, and there was a Race/Ethnicity $\times$ Gender interaction, $F(1,4625)=66.36$, $p<.0001$. Mean $\mathrm{FEV}_{1}$ and FVC were highest in White men, followed by Black men, White women, and Black women. In simple correlations of hostility and contributors to pulmonary function (see Table 2), significantly higher levels of hostility were associated with being younger, shorter (males only), less educated, and more likely to be a current smoker.

To estimate the associations between hostility and pulmonary function, we conducted multiple linear regression analyses with percent predicted $\mathrm{FEV}_{1}$ and $\mathrm{FVC}$ as the outcomes. In full group analyses, each $1 S D$ increase in hostility was associated with a $0.66 \%$ decrease in $\operatorname{FEV}_{1}(p=.0002)$ and a $0.60 \%$ decrease in
FVC ( $p=.0006)$. As shown by Table 3 , each $1 S D$ increase in hostility predicted statistically significant reductions in pulmonary function for Black women, White women, and Black men. For White men, hostility showed no statistically significant effect on pulmonary function, although the pattern of associations between hostility and pulmonary function for White men was in the same direction as the patterns of the other three groups. Further, post hoc three-way interactions of hostility, race/ethnicity, and gender predicting $\operatorname{FEV}_{1}(b=-0.35)$ and $\operatorname{FVC}(b=-0.33)$ were each nonsignificant. Inspection of the means of $\mathrm{FEV}_{1}$ as a function of hostility quintiles - stratified by race/ethnicity and gender (data not shown)-revealed that each quintile increase in hostility is associated with a generally consistent linear decrease in $\mathrm{FEV}_{1}$, for all groups. This inverse association of hostility with pulmonary function is maintained after controlling for age and height, as well as current SES, participant smoking status, and asthma. Despite group differences in absolute levels of hostility and pulmonary function (see Table 1), the patterning of the association between hostility and pulmonary function is similar across all the groups.

\section{Discussion}

These findings suggest an association between hostility and pulmonary function, such that higher levels of hostility are related to lower levels of pulmonary function, in a healthy young adult sample. These effects are robust across two indices of pulmonary function (percent predicted $\mathrm{FEV}_{1}$ and FVC), even after controlling for age, height, current SES, smoking, and asthma. As shown in Table 3 , increased levels of hostility were associated with lower levels of percent predicted $\mathrm{FEV}_{1}$ (from $0.31 \%$ to $1.01 \%$ less than predicted) and FVC (from $0.24 \%$ to $0.85 \%$ less than predicted) per

Table 1

Descriptive Statistics by Race/Ethnicity and Gender

\begin{tabular}{|c|c|c|c|c|c|c|c|c|c|c|c|c|}
\hline \multirow[b]{2}{*}{ Variable } & \multicolumn{3}{|c|}{$\begin{array}{l}\text { Black women } \\
(n=1,293)\end{array}$} & \multicolumn{3}{|c|}{$\begin{array}{l}\text { White women } \\
(n=1,187)\end{array}$} & \multicolumn{3}{|c|}{$\begin{array}{l}\text { Black men } \\
(n=1,054)\end{array}$} & \multicolumn{3}{|c|}{$\begin{array}{l}\text { White men } \\
(n=1,095)\end{array}$} \\
\hline & $M$ & $S D$ & $\%$ & $M$ & $S D$ & $\%$ & $M$ & $S D$ & $\%$ & $M$ & $S D$ & $\%$ \\
\hline Hostility & 20.83 & 8.19 & & 16.12 & 7.97 & & 23.63 & 8.24 & & 18.05 & 7.92 & \\
\hline \multicolumn{13}{|l|}{ Pulmonary function } \\
\hline \multicolumn{13}{|l|}{$\mathrm{FEV}_{1}$} \\
\hline Liters & 2.84 & 0.43 & & 3.30 & 0.44 & & 3.78 & 0.58 & & 4.42 & 0.61 & \\
\hline$\%$ predicted & 98.84 & 12.74 & & 98.50 & 10.55 & & 96.40 & 12.77 & & 96.35 & 10.90 & \\
\hline \multicolumn{13}{|l|}{ FVC } \\
\hline Liters & 3.36 & 0.50 & & 3.95 & 0.54 & & 4.61 & 0.69 & & 5.49 & 0.75 & \\
\hline$\%$ predicted & 101.45 & 12.45 & & 100.89 & 10.81 & & 99.40 & 12.34 & & 98.65 & 10.20 & \\
\hline \multicolumn{13}{|l|}{ Contributors to pulmonary function } \\
\hline Age (years) & 24.47 & 3.87 & & 25.52 & 3.38 & & 24.23 & 3.75 & & 25.47 & 3.36 & \\
\hline Height $(\mathrm{cm})$ & 163.65 & 6.80 & & 165.14 & 6.33 & & 177.08 & 6.92 & & 178.09 & 6.88 & \\
\hline Current SES (years education) & 13.13 & 1.77 & & 14.57 & 2.25 & & 12.91 & 1.90 & & 14.68 & 2.51 & \\
\hline \multicolumn{13}{|l|}{ Smoking status } \\
\hline Ever smoker & & & 9.05 & & & 20.39 & & & 9.20 & & & 15.71 \\
\hline Current smoker & & & 31.86 & & & 27.72 & & & 37.29 & & & 26.12 \\
\hline \multicolumn{13}{|l|}{ Asthma ${ }^{a}$} \\
\hline Symptoms & & & 5.96 & & & 4.80 & & & 2.66 & & & 3.56 \\
\hline Diagnosis or medications & & & 9.36 & & & 7.41 & & & 10.63 & & & 8.40 \\
\hline
\end{tabular}

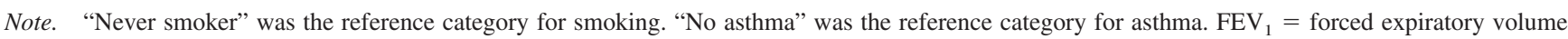
in 1 second; FVC = forced vitality capacity; SES = socioeconomic status.

${ }^{a}$ Symptoms refers to self-reported asthma symptoms without asthma diagnosis, namely shortness of breath "when hurrying on the level or walking up a slight hill" in conjunction with wheezing (either apart from colds or most days or nights). Diagnosis or medications refers to self-reported doctor or nurse diagnosis of asthma or taking of asthma medication (medicine containers checked), regardless of symptoms. 
Table 2

Correlations of Hostility and Pulmonary Function With Study Variables by Race/Ethnicity and Gender

\begin{tabular}{|c|c|c|c|c|c|c|c|c|c|c|c|c|}
\hline \multirow[b]{2}{*}{ Variable } & \multicolumn{3}{|c|}{ Black women $(n=1,293)$} & \multicolumn{3}{|c|}{ White women $(n=1,187)$} & \multicolumn{3}{|c|}{ Black men $(n=1,054)$} & \multicolumn{3}{|c|}{ White men $(n=1,095)$} \\
\hline & Hostility & $\mathrm{FEV}_{1}(\mathrm{~L})$ & FVC (L) & Hostility & $\mathrm{FEV}_{1}(\mathrm{~L})$ & FVC (L) & Hostility & $\mathrm{FEV}_{1}(\mathrm{~L})$ & FVC (L) & Hostility & $\mathrm{FEV}_{1}(\mathrm{~L})$ & FVC (L) \\
\hline $\mathrm{FEV}_{1}(\mathrm{~L})$ & $-.07^{*}$ & - & $.89^{* * * *}$ & $-.07^{*}$ & - & $.85^{* * *}$ & $-.09^{* *}$ & - & $.85^{* * * *}$ & $-.08^{*}$ & - & $.83^{* * *}$ \\
\hline $\mathrm{FEV}_{1}(\% \mathrm{P})$ & $-.09^{* * *}$ & $.82^{* * * *}$ & $.66^{* * * *}$ & $-.07^{*}$ & $.84^{* * * *}$ & $.64^{* * * *}$ & $-.09^{* *}$ & $.84^{* * * *}$ & $.63^{* * * *}$ & -.05 & $.83^{* * * *}$ & $.57^{* * * *}$ \\
\hline $\mathrm{FVC}(\mathrm{L})$ & $-.06^{*}$ & $.89^{* * *}$ & - & $-.06^{*}$ & $.85^{* * * *}$ & - & $-.10^{* *}$ & $.85^{* * *}$ & - & $-.08^{* *}$ & $.83^{* * * *}$ & - \\
\hline $\mathrm{FVC}(\% \mathrm{P})$ & $-.07^{* * *}$ & $.69^{* * * *}$ & $.79^{* * * *}$ & $-.05^{\dagger}$ & $.66^{* * * *}$ & $.82^{* * * *}$ & $-.09^{* * *}$ & $.65^{* * * *}$ & $.81^{* * * *}$ & -.04 & $.62^{* * * *}$ & $.79^{* * * *}$ \\
\hline Age & $-.13^{* * * *}$ & $-.08^{* *}$ & .02 & $-.10^{* * *}$ & -.04 & $.07^{*}$ & $-.16^{* * * *}$ & -.00 & $.09^{* * *}$ & $-.07^{*}$ & $-.12^{* * * *}$ & -.03 \\
\hline Height & -.02 & $.51^{* * * *}$ & $.57^{* * * *}$ & -.04 & $.58^{* * * *}$ & $.62^{* * *}$ & $-.07^{*}$ & $.53^{* * *}$ & $.59^{* * *}$ & $-.08^{* *}$ & $.57^{* * * *}$ & $.65^{* * *}$ \\
\hline Current SES & $-.25^{* * * *}$ & .03 & .04 & $-.14^{* * *}$ & .03 & .03 & $-.27^{* * * *}$ & $.11^{* * * *}$ & $.13^{* * * *}$ & $-.13^{* * *}$ & $.06^{*}$ & $.06^{*}$ \\
\hline Current smoker & $.21^{* * * *}$ & $-.09^{* *}$ & -.03 & $.13^{* * *}$ & $-.07^{*}$ & .01 & $.16^{* * * *}$ & -.04 & .00 & $.15^{\text {*** }}$ & $-.11^{* * *}$ & $-.07^{*}$ \\
\hline Asthma & .04 & $-.11^{* * * *}$ & -.03 & -.00 & $-.13^{* * *}$ & -.03 & .04 & $-.17^{* * *}$ & -.04 & .04 & $-.13^{* * *}$ & -.02 \\
\hline
\end{tabular}

Note. Current smoker was coded so that $0=$ not a current smoker, and $1=$ current smoker. Asthma was coded so that $0=$ no symptoms; $1=$ self-reported asthma symptoms without asthma diagnosis, namely shortness of breath "when hurrying on the level or walking up a slight hill" in conjunction with wheezing (either apart from colds or most days or nights); and 2 = self-reported doctor or nurse diagnosis of asthma or taking of asthma medication (medicine containers checked), regardless of symptoms. $\mathrm{FEV}_{1}=$ forced expiratory volume in $1 \mathrm{~s} ; \mathrm{L}=$ liters; $\mathrm{FVC}=\mathrm{forced}$ vitality capacity; $\% \mathrm{P}=$ percent predicted; SES = socioeconomic status.

${ }^{\dagger} p<.10 .{ }^{*} p<.05 .{ }^{* * *} p<.01{ }^{* * * *} p<.001$.

$1 S D$ increase in hostility score. Although the levels of hostility in this sample are higher among Blacks than Whites and among men than women, the association between hostility and pulmonary function is significant across three of the four race/ethnicity and gender groups (Black women, White women, Black men) examined and in the same direction for White men.

Young adulthood is a time of continued change: socially, psychologically, and physically. As such, it is interesting to find a relatively consistent pattern of results during this period across race/ethnicity and gender. Although the absolute values of the slopes of pulmonary function across hostility are small, note that in full-sample analyses, they remain statistically significant after accounting for an array of possible confounders. Even being a current smoker does not show an association with pulmonary function in this relatively young, healthy sample. Effects of hostility, like smoking, are posited to accumulate over the course of many years, gradually taking a toll on health. In fact, we expect any incremental difference seen in this young a sample only to be amplified over time. Given that $\mathrm{FEV}_{1}$ is a marker of upper airway functioning and FVC a marker of total lung volume, it is not surprising that the association of hostility appears to be stronger with $\mathrm{FEV}_{1}$ and evident to a lesser degree with FVC. The upper airways are constantly responding to environmental demands (e.g., cold, air particles, and stress), whereas total lung volume changes over a much longer time frame (e.g., months and years, depending on the phase in lung development over the life course). In subsequent work with follow-up through older adulthood, it will be important to ascertain whether hostility predicts change over time and ultimately disease outcomes like COPD, as well as whether these effects hold across race/ethnicity and gender groups.

Although for White men the decrements in pulmonary function by hostility were not as large as those in other groups, or enough to be statistically significant, when we examine mean pulmonary function by quintile of hostility (data not shown), similar to the other three groups, we see a trend of a gradient effect between higher levels of hostility and lower pulmonary function for this group. Were this a true effect, we might expect to see effects of hostility on pulmonary function for White men appear later in life.
Our team is beginning to examine this possibility with other data. Put differently, the association between higher hostility and lower pulmonary function may hold for all four groups but could be accelerated in lower status groups. This is consistent with the notion of "weathering" (Geronimus, 2001), which has been used to conceptualize the earlier origins of health problems for Black versus White American women in other health domains.

We do not have the data here to fully understand this finding, although we can speculate about mechanisms. One explanation may be that displayed hostility among Black women, White women, and Black men is met with harsher social sanctions than among White men. Of interest, behavioral displays that are interpreted as hostile when enacted by members of lower status groups may be seen as markers of authority when enacted by members of high-status groups. Indeed, research suggests that there are normative expectations for people to display anger in high-status roles (Tiedens, 2001), which then reinforces their status roles. People in lower status roles who act in violation of role expectations (e.g., displaying hostility as a woman or person of color) may elicit social ramifications far more negative or punishing than those for people acting in accord with social expectations (Tiedens, 2001), resulting in heightened stress, which in turn may compromise pulmonary function (Wright, Rodriguez, \& Cohen, 1998). Another pathway by which those in lower social positions may come to experience greater hostility arises from lower status groups contending with more adversity and thus having more opportunities to experience hostility.

It is interesting to speculate about whether the association of hostility and pulmonary function is modified by race/ethnicity and gender, but we are cautious about overstating the meaning of the nonsignificant findings for White men. The finding that hostility is associated with lower pulmonary function seems robust given that it holds even after accounting for an array of covariates and in full-group analyses as well as three of the four subgroup analyses. It is important to keep in mind that in post hoc full-group analyses, the interaction of hostility, race/ethnicity, and gender itself was not statistically significant. 
Table 3

Parameter Estimates for Hostility and Covariates Predicting Pulmonary Function

\begin{tabular}{|c|c|c|c|c|c|c|c|c|}
\hline \multirow[b]{3}{*}{ Predictors } & \multicolumn{4}{|c|}{$\mathrm{FEV}_{1} \%$ predicted } & \multicolumn{4}{|c|}{ FVC $\%$ predicted } \\
\hline & \multicolumn{2}{|c|}{ Model 1} & \multicolumn{2}{|c|}{ Model 2} & \multicolumn{2}{|c|}{ Model 1} & \multicolumn{2}{|c|}{ Model 2} \\
\hline & $b$ & $S E$ & $b$ & $S E$ & $b$ & $S E$ & $b$ & $S E$ \\
\hline & \multicolumn{8}{|c|}{ Black women $(n=1,293)$} \\
\hline Intercept & $105.69^{* * * *}$ & 17.43 & $104.43^{* * *}$ & 17.27 & $119.64^{* * * *}$ & 17.06 & $119.29^{* * * *}$ & 17.05 \\
\hline Hostility $^{\text {a }}$ & $-1.10^{* *}$ & 0.36 & $-0.83^{*}$ & 0.37 & $-0.85^{*}$ & 0.35 & $-0.78^{*}$ & 0.37 \\
\hline Age & 0.95 & 1.25 & 1.01 & 1.26 & -0.19 & 1.22 & -0.07 & 1.24 \\
\hline Age squared & -0.02 & 0.03 & -0.02 & 0.03 & 0.01 & 0.03 & -0.00 & 0.03 \\
\hline Height & $-0.11^{*}$ & 0.05 & $-0.10^{\dagger}$ & 0.05 & $-0.10^{\dagger}$ & 0.05 & $-0.09^{\dagger}$ & 0.05 \\
\hline Current SES & & & -0.02 & 0.21 & & & -0.10 & 0.21 \\
\hline \multicolumn{9}{|l|}{ Smoking status } \\
\hline Ever smoker & & & 1.08 & 1.28 & & & $2.48^{*}$ & 1.26 \\
\hline Current smoker & & & -1.03 & 0.82 & & & 0.39 & 0.81 \\
\hline \multicolumn{9}{|l|}{ Asthma } \\
\hline Symptoms & & & $-5.14^{* * *}$ & 1.51 & & & $-3.42^{*}$ & 1.49 \\
\hline \multirow[t]{2}{*}{ Diagnosis or medications } & & & $-4.99^{* * * *}$ & 1.21 & & & -1.49 & 1.19 \\
\hline & \multicolumn{8}{|c|}{ White women $(n=1,187)$} \\
\hline Intercept & $42.97^{*}$ & 17.57 & $45.57^{* * *}$ & 17.45 & $50.11^{* *}$ & 18.03 & $51.82^{* *}$ & 18.09 \\
\hline Hostility $^{\text {a }}$ & $-0.69^{*}$ & 0.31 & $-0.63^{*}$ & 0.31 & -0.47 & 0.31 & $-0.54^{\dagger}$ & 0.32 \\
\hline Age & $3.24^{*}$ & 1.28 & $3.12^{*}$ & 1.30 & $2.75^{*}$ & 1.32 & $2.66^{*}$ & 1.35 \\
\hline Age squared & $-0.06^{*}$ & 0.03 & $-0.06^{*}$ & 0.03 & $-0.05^{\dagger}$ & 0.03 & $-0.05^{\dagger}$ & 0.03 \\
\hline Height & $0.09^{\dagger}$ & 0.05 & $0.09^{\dagger}$ & 0.05 & $0.09^{\dagger}$ & 0.05 & $0.10^{\dagger}$ & 0.05 \\
\hline Current SES & & & -0.00 & 0.15 & & & -0.10 & 0.16 \\
\hline \multicolumn{9}{|l|}{ Smoking status } \\
\hline Ever smoker & & & $1.78^{*}$ & 0.80 & & & $2.10^{*}$ & 0.83 \\
\hline Current smoker & & & $-1.41^{\dagger}$ & 0.76 & & & 0.74 & 0.79 \\
\hline \multicolumn{9}{|l|}{ Asthma } \\
\hline Symptoms & & & $-2.70^{\dagger}$ & 1.45 & & & -1.31 & 1.50 \\
\hline \multirow[t]{2}{*}{ Diagnosis or medications } & & & $-4.27^{* * *}$ & 1.15 & & & -0.12 & 1.20 \\
\hline & \multicolumn{8}{|c|}{ Black men $(n=1,054)$} \\
\hline Intercept & $74.02^{* * * *}$ & 19.93 & $77.10^{\text {**** }}$ & 19.71 & $52.98^{* *}$ & 19.08 & $54.99^{* *}$ & 19.13 \\
\hline Hostility $^{\mathrm{a}}$ & $-0.93^{*}$ & 0.40 & $-0.74^{\dagger}$ & 0.40 & $-0.71^{\dagger}$ & 0.37 & $-0.66^{\dagger}$ & 0.39 \\
\hline Age & 2.09 & 1.45 & 1.86 & 1.45 & $3.70^{* *}$ & 1.39 & $3.45^{*}$ & 1.41 \\
\hline Age squared & -0.03 & 0.03 & -0.03 & 0.03 & $-0.06^{*}$ & 0.03 & $-0.06^{*}$ & 0.03 \\
\hline Height & -0.03 & 0.06 & -0.05 & 0.06 & -0.01 & 0.05 & -0.02 & 0.05 \\
\hline Current SES & & & 0.29 & 0.23 & & & 0.20 & 0.23 \\
\hline \multicolumn{9}{|l|}{ Smoking status } \\
\hline Ever smoker & & & 0.67 & 1.38 & & & 1.71 & 1.34 \\
\hline Current smoker & & & 0.14 & 0.88 & & & 1.22 & 0.85 \\
\hline Asthma & & & & & & & & \\
\hline Symptoms & & & -2.87 & 2.41 & & & -2.77 & 2.34 \\
\hline Diagnosis or medications & & & $-7.13^{* * *}$ & 1.25 & & & -0.75 & 1.21 \\
\hline & & & & White $\mathrm{m}$ & $=1,095)$ & & & \\
\hline Intercept & $75.80^{* * * *}$ & 18.99 & $82.64^{* * * *}$ & 18.93 & $50.86^{* *}$ & 17.72 & $51.67^{* *}$ & 17.87 \\
\hline Hostility $^{\mathrm{a}}$ & -0.48 & 0.33 & -0.31 & 0.33 & -0.31 & 0.31 & -0.24 & 0.31 \\
\hline Age & 1.45 & 1.42 & 0.86 & 1.44 & $2.69^{*}$ & 1.33 & $2.67^{*}$ & 1.36 \\
\hline Age squared & -0.03 & 0.03 & -0.02 & 0.03 & $-0.05^{\dagger}$ & 0.03 & $-0.05^{\dagger}$ & 0.03 \\
\hline Height & 0.03 & 0.05 & 0.02 & 0.05 & $0.08^{\dagger}$ & 0.04 & $0.07^{\dagger}$ & 0.05 \\
\hline Current SES & & & 0.17 & 0.15 & & & 0.02 & 0.14 \\
\hline Smoking status & & & & & & & & \\
\hline Ever smoker & & & $1.85^{*}$ & 0.94 & & & $2.01^{*}$ & 0.89 \\
\hline Current smoker & & & -0.92 & 0.83 & & & 0.10 & 0.79 \\
\hline Asthma & & & & & & & & \\
\hline Symptoms & & & -2.76 & 1.80 & & & $-3.22^{\dagger}$ & 1.70 \\
\hline Diagnosis or medications & & & $-5.41^{* * *}$ & 1.18 & & & -0.26 & 1.11 \\
\hline
\end{tabular}

Note. Predictors in Model 1 are hostility, age, age squared, and height. Predictors in Model 2 include those in Model 1 and current SES, participant's smoking status (reference group is never smoker), and asthma (reference group is no asthma; comparison groups are [a] self-reported asthma symptoms without asthma diagnosis, namely shortness of breath "when hurrying on the level or walking up a slight hill" in conjunction with wheezing [either apart from colds or most days or nights] and [b] self-reported doctor or nurse diagnosis or taking of asthma medications [medicine containers checked], regardless of symptoms). $\mathrm{FEV}_{1}=$ forced expiratory volume in $1 \mathrm{~s} ; \mathrm{FVC}=$ forced vitality capacity; SES $=$ socioeconomic status.

${ }^{a}$ Hostility is scaled to represent the effect of a 1 standard deviation $(S D)$ change on the outcome pulmonary function variable; thus, slopes are in units of percent predicted per standard deviation.

Standard deviations are listed in Table 1 and are approximately 8 units on the Cook-Medley scale for each race/ethnicity and gender group.

${ }^{\dagger} p<.10 .{ }^{*} p<.05 .{ }^{* *} p<.01 .{ }^{* * *} p<.001$. 
We controlled for smoking; however, smoking itself may be on the causal pathway between hostility and pulmonary function. It could be that individuals with high levels of hostility are more likely to smoke as a form of coping with emotional distress (Siegler et al., 2003). Further, individuals higher on hostility may begin smoking at an earlier age and smoke in heavier doses. If smoking attenuates the relationship between hostility and pulmonary function, then controlling for smoking would result in an underestimate of the hostility-pulmonary function association. Given that our final models included smoking, this suggests that our analyses may be particularly conservative.

We cannot make causal claims, of course, with cross-sectional data. It could be that lower pulmonary function causes greater hostility. However, this seems unlikely. Although there is variability among participants in this sample, they have relatively normal levels of pulmonary function expected for this age range (cf. Wang et al., 2004). Another explanation for the findings may be that some third variable we did not account for contributes to both hostility and pulmonary function. For example, environmental toxins may both increase hostility and decrease pulmonary function. We were not able to investigate this hypothesis in the current study. Moreover, findings are consistent with other research that finds a role for hostility in the development of major health outcomes (Miller et al., 1996). Importantly, one advantage of using pulmonary function as an index of health is that it can be objectively and reliably measured over a wide range of values. Thus, it is less susceptible to the problem of restricted range, also referred to as disease-based spectrum bias (Miller et al., 1996), that has been found in research on the effects of hostility on congenital heart disease. That is, research on hostility and congenital heart disease that examines associations in high-risk populations may show attenuated relationships between hostility and disease because, by definition, there is less between-subjects variability in the outcome compared to a less restricted population.

This study is the first to make a detailed examination of the inverse link between hostility and pulmonary function; further, it examines this link in relation to race/ethnicity and gender. It appears that harboring hostility hurts, insofar as it is associated with lowered pulmonary function. More research is needed to establish whether hostility is prospectively associated with change in pulmonary function or is associated with pulmonary function at other points in the life course, especially during older adulthood. As well, the possible influence of social status on personality functioning and in turn pulmonary health deserves further exploration.

\section{References}

Apostol, G. G., Jacobs, D. R., Jr., Tsai, A. W., Crow, R. S., Williams, O. D., Townsend, M. C., \& Beckett, W. S. (2002). Early life factors contribute to the decrease in lung function between ages 18 and 40: The Coronary Artery Risk Development in Young Adults Study. American Journal of Respiratory and Critical Care Medicine, 166, 166-172.

Atmaca, M., Kuloglu, M., Tezcan, E., Gecici, O., \& Ustundag, B. (2002). Serum cholesterol and leptin levels in patients with borderline personality disorder. Neuropsychobiology, 45, 167-171.

Butovskaya, M. L., Boyko, E. Y., Selverova, N. B., \& Ermakova, I. V. (2005). The hormonal basis of reconciliation in humans. Journal of Physiological Anthropology and Applied Human Science, 24, 333-337.
Calverley, P., \& Walker, P. (2003). Chronic obstructive pulmonary disease. Lancet, 362, 1053-1061.

Cohen, S., \& Rodriguez, M. S. (1995). Pathways linking affective disturbances and physical disorders. Health Psychology, 14, 374-380.

Cook, W., \& Medley, D. (1954). Proposed Hostility and Pharisaic-Virtue scales for the MMPI. Journal of Applied Psychology, 38, 414-418.

Cooper, M., Frone, M., Russell, M., \& Mudar, P. (1995). Drinking to regulate positive and negative emotions: A motivational model of alcohol use. Journal of Personality and Social Psychology, 69, 990-1005.

Crockett, A., Cranston, J., Moss, J., \& Alpers, J. (2002). The impact of anxiety, depression and living alone in chronic obstructive pulmonary disease. Quality of Life Research, 11, 309-316.

Donaldson, G. C., Seemungal, T. A., Patel, I. S., Bhowmik, A., Wilkinson, T. M., Hurst, J. R., et al. (2005). Airway and systemic inflammation and decline in lung function in patients with COPD. Chest, 128, 1995-2004.

Everson, S. A., Kauhanen, J., Kaplan, G. A, Goldberg, D. E., Julkunen, J., Tuomilehto, J., \& Salonen, J. T. (1997). Hostility and increased risk of mortality and acute myocardial infarction: The mediating role of behavioral risk factors. American Journal of Epidemiology, 146, 142-152.

Friedman, G. D., Cutter, G. R., Donahue, R. P., Hughes, G. H., Hulley, S. B., Jacobs, D. R., Jr., et al. (1988). CARDIA: Study design, recruitment, and some characteristics of the examined subjects. Journal of Clinical Epidemiology, 41, 1105-1116.

Geronimus, A. T. (2001). Understanding and eliminating racial inequalities in women's health in the United States: The role of the weathering conceptual framework. Journal of the American Medical Women's Association, $56,133-136$.

Hankinson, J. L., Odencrantz, J. R., \& Fedan, K. B. (1999). Spirometric reference values from a sample of the general U.S. population. American Journal of Respiratory and Critical Care Medicine, 159, 179-187.

Higgins, M., Keller, J. B., Wagenknecht, L. E., Townsend, M. C., Sparrow, D., Jacobs, D. R., Jr., \& Hughes, G. (1991). Pulmonary function and cardiovascular risk factor relationships in Black and in White young men and women. Chest, 99, 315-322.

Houston, B. K., \& Vavak, C. R. (1991). Cynical hostility: Developmental factors, psychosocial correlates, and health. Health Psychology, 10, $9-17$.

Hughes, J. W., Sherwood, A., Blumenthal, J. A., Suarez, E. C., \& Hinderliter, A. L. (2003). Hostility, social support, and adrenergic receptor responsiveness among African-American and White men and women. Psychosomatic Medicine, 65, 582-587.

Hurd, S. (2000). The impact of COPD on lung health worldwide: Epidemiology and incidence. Chest, 117, 764-772.

Jackson, B., Cooper, M., Mintz, L., \& Albino, A. (2003). Motivations to eat: Scale development and validation. Journal of Research in Personality, 37, 297-318.

Katon, W., Richardson, L., Lozano, P., \& McCauley, E. (2004). The relationship of asthma and anxiety disorders. Psychosomatic Medicine, 66, 349-355.

Kubzansky, L. D., Wright, R. J., Cohen, S., Weiss, S., Rosner, B., \& Sparrow, D. (2002). Breathing easy: A prospective study of optimism and pulmonary function in the Normative Aging Study. Annals of Behavioral Medicine, 24, 345-353.

Miller, T. Q., Smith, T. W., Turner, C. W., Guijarro, M. L., \& Hallet, A. J. (1996). A meta-analytic review of research on hostility and physical health. Psychological Bulletin, 119, 322-348.

Murray, C. J., \& Lopez, A. D. (1997). Alternative projections of mortality and disability by cause 1990-2020: Global Burden of Disease Study. Lancet, 349, 1498-1504.

Niaura, R., Banks, S. M., Ward, K. D., Stoney, C. M., Spiro, A., III, Aldwin, C. M., et al. (2000). Hostility and the metabolic syndrome in older males: The Normative Aging Study. Psychosomatic Medicine, 62, 7-16.

Pelkonen, M., Notkola, I.-L., Tukiainen, H., Tervahauta, M., Tuomilehto, 
J., \& Nissinen, A. (2001). Smoking cessation, decline in pulmonary function and total mortality: A 30 year follow up study among the Finnish cohorts of the Seven Countries Study. Thorax, 56, 703-707.

Pollitt, R. A., Daniel, M., Kaufman, J. S., Lynch, J. W., Salonen, J. T., \& Kaplan, G. A. (2005). Mediation and modification of the association between helplessness, hostility, and progression of carotid atherosclerosis. Journal of Behavioral Medicine, 28, 53-64.

Ritz, T., \& Steptoe, A. (2000). Emotion and pulmonary function in asthma: Reactivity in the field and relationship with laboratory induction of emotion. Psychosomatic Medicine, 62, 808-815.

Scherwitz, L., Perkins, L., Chesney, M., \& Hughes, G. (1991). CookMedley Hostility Scale and subsets: Relationship to demographic and psychosocial characteristics in young adults in the CARDIA study. Psychosomatic Medicine, 53, 36-49.

Senior, R. M., \& Anthonisen, N. R. (1998). Chronic obstructive pulmonary disease (COPD). American Journal of Respiratory and Critical Care Medicine, 157, S139-S147.

Sidanius, J., \& Pratto, F. (1999). Social dominance: An intergroup theory of social hierarchy and oppression. New York: Cambridge University Press.

Siegler, I. C., Costa, P. T., Brummett, B. H., Helms, M. J., Barefoot, J. C., Williams, R. B., et al. (2003). Patterns of change in hostility from college to midlife in the UNC Alumni Heart Study predict high-risk status. Psychosomatic Medicine, 65, 738-745.

Sin, D., \& Man, S. (2003). Impaired lung function and serum leptin in men and women with normal body weight: A population based study. Tho$\operatorname{rax}, 58,695-698$.
Sparrow, D., O'Connor, G. T., Rosner, B., Demolles, D., \& Weiss, S. T. (1993). A longitudinal study of plasma cortisol concentration and pulmonary function decline in men. American Review of Respiratory Disease, 147, 1345-1348.

Tiedens, L. Z. (2001). Anger and advancement versus sadness and subjugation: The effect of negative emotion expressions on social status conferral. Journal of Personality and Social Psychology, 80, 86-94.

Tolan, P. H., Gorman-Smith, D., Henry, D., Chung, K.-S. \& Hunt, M. (2002). The relation of patterns of coping of inner-city youth to psychopathology symptoms. Journal of Research on Adolescence, 12, 423449.

van der Velden, V., \& Hulsmann, A. (1999). Autonomic innervation of human airways: Structure, function, and pathophysiology in asthma. Neuroimmunomodulation, 6, 145-159.

Wang, X., Mensinga, T. T., Schouten, J. P., Rijcken, B., \& Weiss, S. T. (2004). Determinants of maximally attained level of pulmonary function. American Journal of Respiratory and Critical Care Medicine, 169, 941-949.

Weiss, S. T. (1991). Pulmonary function as a phenotype physiologic marker of cardiovascular morbidity and mortality. Chest, 99, 265-266.

Wright, R. J., Rodriguez, M., \& Cohen, S. (1998). Review of psychosocial stress and asthma: An integrated biopsychosocial approach. Thorax, 53 1066-1074.

Yan, L. L., Liu, K., Matthews, K. A., Daviglus, M. L., Ferguson, T. F., \& Kiefe, C. I. (2003). Psychosocial factors and risk of hypertension: The Coronary Artery Risk Development in Young Adults (CARDIA) Study. Journal of the American Medical Association, 290, 2138-2148. 